\title{
Directory of Residency and Fellowship Programs in Women's Health
}

Mission: The mission of the AAWHP is to improve the health of women through leadership in research, education, clinical models, and community partnerships. This mission is carried out through networking, leadership and mentoring, collaborative projects, lobbying and advocacy, political and social commentary, education of policymakers, partnership with national organizations, and creation of innovative models.

May 2008 


\section{Contents}

\section{Overview}

\section{Residencies in Women's Health}

Jacobi Medical Center/Albert Einstein College of Medicine (NY) 674

Massachusetts General Hospital/Harvard University School of Medicine (MA) 675

Michigan State University College of Human Medicine (MI) 676

Rochester General Hospital (NY) 677

Tulane University School of Medicine (LA) $\quad 678$

University of Alabama Hospital in Birmingham (AL) 679

$\begin{array}{ll}\text { University of Kentucky (KY) } & 680\end{array}$

University of Pittsburgh Medical Center/ $\quad 681$

University of Pittsburgh School of Medicine (PA)

Virginia Commonwealth University Medical Center (VA) 682

(formerly Medical College of Virginia)

\section{Fellowships in Women's Health}

Aurora Health Care Programs (WI) 684

Boston Medical Center Hospital/VA Boston Healthcare System/ 685

Boston University School of Medicine (MA)

Brody School of Medicine at East Carolina University (NC) 686

Cedars-Sinai Medical Center (CA) 687

Cleveland Clinic Foundation $(\mathrm{OH}) \quad 689$

Durham Veterans Affairs Medical Center/Duke University School of Medicine (NC) 690

MacNeal Hospital (IL) $\quad 691$

Marshall University School of Medicine (WV) 692

Mayo Clinic College of Medicine (MN) $\quad 693$

Pittsburgh Veterans Affairs Medical Center/University of Pittsburgh School 694 of Medicine (PA)

Portland Veterans Affairs Medical Center/Oregon Health and Science University (OR) 695

San Francisco Veterans Affairs Medical Center/University of California at 696 San Francisco School of Medicine (CA)

UCSF Women's Health Clinical Research Center/University of California 697 San Francisco (CA)

Texas Tech University Health Sciences Center (TX) 698

Texas Tech University Health Sciences Center-El Paso (TX) 699

University of California, Davis School of Medicine (CA) 700

University Hospitals Case Medical Center $(\mathrm{OH}) \quad 701$

University of Illinois at Chicago College of Medicine (IL) 702

University of Medicine and Dentistry of New Jersey/Robert Wood Johnson 703 Medical School (NJ)

University of Michigan School of Medicine (MI) $\quad 704$

University of Wisconsin School of Medicine/Veterans Affairs Medical Center (WI) 705

VA Greater Los Angeles Healthcare System (CA) 706

\section{Integrated Residency Models}

$\begin{array}{ll}\text { Drexel University College of Medicine (PA) } & 708\end{array}$

$\begin{array}{ll}\text { (formerly MCP Hahnemann University School of Medicine) } & 709\end{array}$

$\begin{array}{ll}\text { Long Island Jewish Medical Center (NY) } & 710\end{array}$ 


\section{Overview}

$\mathbf{I}^{\mathrm{n}}$ support of interdisciplinary Women's Health training programs, the Journal of Women's Health is pleased to publish the Directory of Women's Health Residencies and Fellowships. The Directory was initially developed under the direction of Dr. Saralyn Mark from a national survey of 1,355 hospitals conducted in September 1995. Information from the Association of American Medical Colleges, the American Association of Colleges of Osteopathic Medicine, and the American Hospital Association was used to identify institutions approved for Women's Health residency and fellowship programs. The following are criteria for inclusion of residency and fellowship programs in the directory:

1) The program should be interdisciplinary in nature, crossing traditional boundaries, in order to comprehensively focus on a wide range of women's health concerns and issues, including, but not limited to, mental health, aging, reproductive health, urogynecology, gender differences in disease presentation and treatment, bone health, heart health, and breast health.

2) The program should have a separate application process with its own director within an academic medical center.

3) To qualify as a residency program in women's health, the program should offer a specialized curriculum in women's health in addition to the required activities of a traditional residency track.

The Directory was previously published by the Office on Women's Health in the Department of Health and Human Services in 1995, and has been updated annually since then. In 2004, the Association of Academic Women's Health Programs (AAWHP) assumed responsibility for maintaining and updating the directory. AAWHP is a national non-profit organization whose members include women's health educators, researchers, and program directors at academic institutions. Its mission is to improve the health of women through leadership in research, education, clinical models, and community partnerships and to accelerate translation of research into clinical practice. This mission is carried out through networking, leadership and mentoring, collaborative projects, advocacy, political and social commentary, education of policymakers, partnership with national organizations, and creation of innovative models, including Women's Health fellowships and residency programs.

The interdisciplinary programs included in this directory model the integration of educational experiences across departments, such that future physicians can be trained to more effectively provide comprehensive care for women. In addition, Women's Health fellowships are a breeding ground for new researchers in this field. The publication of the Directory will help to disseminate program information and foster awareness of these programs, and will hopefully expand and enhance graduate medical education in the area of Women's Health.

If any training program meets inclusion criteria and has been unintentionally omitted from this directory, AAWHP would like to be promptly notified. The directory will continue to be updated annually as new curricula develop. For questions regarding program inclusion or for information regarding AAWHP, please contact Carolyn Gibson at jwh@vcu.edu. 


\section{Residencies in Women's Health}




Institution(s)
Jacobi Medical Center/ Albert Einstein
College of Medicine
Program Type: General Internal Medicine-
Women's Health Residency Track
Date Established: July 1994
Number of Positions: Up to 4 per year
Duration of Program: 3 years
Sponsored by:
Department of Medicine
Co-Sponsoring Institution(s)/Department(s)
Departments of Obstetrics, Gynecology
and Women's Health
F-mail: Lori.Lemberg@nbhn.net
Track
Docobi Medical Center
1400 Pelham Parkway South
Contact(s)

\section{Eligibility Requirement(s)}

A medical degree is required.

\section{Required Activities}

In addition to the required aspects of the Internal Medicine residency training program, junior/senior residents have weekly gynecology continuity clinic supervised by a gynecologist. They are seeing women for routine gynecological care. There is also a medical consultation clinic weekly dedicated to women for preoperative evaluations prior to surgery. Over their three year training they attend 5 blocks of time devoted to women's health issues. Each "block" lasts approximately one month.

\section{Elective Activities}

Elective options include research in issues related to women's health and rotations in Family Planning, Breast clinic, surgical subspecialty clinics, reproductive endocrinology and infertility clinics.

\section{Special Degree(s)/Certificate(s) Offered}

Residents are board eligible in Internal Medicine.

\section{Goals of the Program}

"Graduates will be board eligible in Internal Medicine and well-qualified to provide primary care to men and women. They will have expertise in the special aspects of women's general and reproductive health. They will be prepared to contribute as educators and researchers in the field of women's health."

\section{Other Program Features}

This is a track (Women's Health) within the Internal Medicine residency program. Clinical and educational activities focus on General Internal Medicine, Health Promotion, Disease Prevention and Epidemiology, Primary Gynecology, Psychology and Psychiatry. The mini-courses offered are: "Cardiovascular Disease and Gender", "Cancer and Gender", and "Rheumatology and Gender" and include reading groups supervised by senior faculty. The program emphasizes the importance of gender, race, age, and socioeconomic status in health and disease.

\section{Reason for Initiating Program}

"This residency track was developed by the Department of Internal Medicine in cooperation with the Departments of Obstetrics, Gynecology and Women's Health. The departments are working together to enrich the education components of their training in the primary care aspects of women's health. Teamwork will lead to further innovations in the care of women." 


Institution(s)
Massachusetts General Hospital/
Harvard University School of Medicine
Program Type: Residency in Women's Health
Date Established: July 1995
Number of Positions: 2 per year
Duration of Program: 3 years
Sponsored by:
Department of Medicine
Co-Sponsoring Institution(s)/Department(s)
Department of Obstetrics and
Gynecology
Telephone: (617) $724-6700$
Yaren Carlson, M.D.
Director of Women's Health Associates
Passachusetts General Hospital
Karen O'Brien, M.D.
Director of Women's Health Focus in
Contact(s)

Eligibility Requirement(s)

A medical degree is required.

\section{Required Activities}

In addition to inpatient rotations in Internal Medicine, residents are required to participate for three to four months each year in a multidisciplinary primary care practice for women. This experience provides ambulatory subspecialty training in Gynecology, Orthopedics, Dermatology, and breast disease.

\section{Elective Activities}

Six- to eight-week electives in Endocrinology, Infectious Disease, Arthritis, and Obstetrics and Gynecology are offered in the third year of residency.

\section{Special Degree(s)/Certificate(s) Offered}

Residents are board eligible in Internal Medicine.

\section{Goals of the Program}

"To provide comprehensive training in ambulatory General Medicine, Gynecology, and other specialties relevant to primary care of women in the context of an inpatient Internal Medicine residency."

\section{Other Program Features}

Formal mentorship programs and mini-courses in clinical and nonclinical topics with specified goals and objectives are available.

\section{Reason for Initiating Program}

"The program was created to expand opportunities within existing primary care residency training to focus on the special needs of women in an integrated, multidisciplinary clinical practice site." 


\section{Institution(s)}

Michigan State University/Kalamazoo Center for Medical Studies

Program Type: Residency in Women's Health

Date Established: 1995

Number of Positions: Variable

Duration of Program: 3 years

Sponsored by:

Department of Medicine

Co-Sponsoring Institution(s)/Department(s):

Department of Pediatrics

Contact(s):

Melissa Davidson, M.D.

Women's Health Director

Ambulatory Clinic Director

1000 Oakland Drive

Kalamazoo, MI 49008

Telephone: (269) 337-6350

FAX: (269) 337-4234

E-mail: davidson@kcms.msu.edu

\section{Eligibility Requirement(s)}

A medical degree is required.

\section{Required Activities}

This program requires the completion of five rotations that are one-month in duration: 1) Adolescent Medicine, 2) Behavioral Medicine, 3) Subspeciality elective with a women's health focus, 4) Perinatology, 5) Advanced Gynecology/Women's Health.

\section{Elective Activities}

Elective activities include women's health research projects, monthly women's health conferences, evening women's health journal club meetings, monthly grand rounds, and an extensive women's health reading curriculum.

\section{Special Degree(s)/Certificate(s) Offered}

A certificate of focused training in women's health is offered.

\section{Goals of the Program}

"To provide additional clinical experiences and evidence-based training in women's health, beyond what is provided in a standard primary care curriculum."

\section{Other Program Features}

Involvement of OB/GYN and surgical specialists in training/educational experiences as well as exposure to complementary and alternative medicine topics.

\section{Reason for Initiating Program}

"There was significant interest among medical students, primary care residents, and faculty associated with our residency programs." 


\section{Institution(s)}

Rochester General Hospital (NY)

Program Type: Internal Medicine Residency, Women's Health Track

Date Established: 1998

Number of Positions: 2 or 3 per year

Duration of Program: 3 years

Sponsored by:

Department of Internal Medicine

Co-Sponsoring Institution(s)/Department(s)

Department of Obstetrics and

Gynecology

Contact(s)

Ruth Kouides, M.D., M.P.H.

Rochester General Hospital

1425 Portland Avenue

Rochester, NY 14621

Telephone: (585) 922-4632

FAX: (585) 922-4922

E-mail: ruth.kouides@viahealth.org

Diane Morse, M.D.

General Medicine Unit

Rochester General Hospital

1425 Portland Avenue

Rochester, NY 14621

Telephone: (585) 922-4368

FAX: (585) 922-4440

E-mail: diane.morse@viahealth.org

\section{Eligibility Requirement(s)}

A medical degree is required.

\section{Required Activities}

Women's health residents will complete the following activities: 1) 2 year continuity clinic in ambulatory gynecology with both Internal Medicine and Obstetrics and Gynecology Attending preceptors, 2) two gynecology rotations, and 3) women's health electives.

\section{Elective Activities}

Residents will have multiple choices in Adolescent Medicine, Geriatrics, Reproductive Endocrinology, Urogynecology, and Breast Health.

\section{Special Degree(s)/Certificate(s) Offered}

Residents are board eligible in Internal Medicine. A women's health concentration certificate is offered.

\section{Goals of the Program}

"To produce excellent internists with special skills and knowledge to improve women's health care."

\section{Other Program Features}

A collaborative lecture series for Internal Medicine and Obstetrics and Gynecology residents.

\section{Reason for Initiating Program}

"This program is a collaboration between the Departments of Internal Medicine and Obstetrics and Gynecology that has been developed to allow internists to pursue special training and knowledge in women's health in the context of an Internal Medicine residency." 
Institution(s):

Tulane University School of Medicine

Program Type: Residency in Women's Health

Date Established: July 1995

Number of Positions: 3 per year

Duration of Program: 3 years

Sponsored by:

Department of Medicine

Co-Sponsoring Institution(s)/Department(s)

New Orleans Veterans Affairs Medical Center

Contact(s)

Jeffrey G. Wiese, M.D., Director Internal Medicine Residency Program Tulane University School of Medicine 1430 Tulane Avenue, SL-50

New Orleans, LA 70112

Telephone: (504) 988-7809

FAX: (504) 488-3971

E-mail: jwiese@tulane.edu

Myra A. Kleinpeter, M.D., M.P.H.

Director, Professional Education

TUXCOE

1430 Tulane Avenue, SL-45

New Orleans, LA 70112

Telephone: (504) 988-5346

FAX: (504) 988-1909

E-mail: mkleinp@tulane.edu

\section{Eligibility Requirement(s)}

A medical degree is required.

\section{Required Activities}

Residents participate in the Internal Medicine internship and weekly rotations in the Veterans Affairs Medical Center's Women's Health Clinic. Additionally, there are one month rotations in the Obstetrics and Gynecology service, an Internal Medicine consultation on this service, as well as a two month rotation in Obstetrics and Gynecology clinics.

\section{Elective Activities}

Elective options include one month rotations in the Student Health Clinic, Breast Health Clinic, Women's GU Clinic, and Infertility Clinic.

\section{Goals of the Program}

The goals of this program are: "1) To train internists to become proficient in managing and screening diseases that impact the health of women; 2) to improve the overall health status of women in health promotion; and 3) to promote disease prevention in women."

\section{Other Program Features}

This is a track within the Internal Medicine residency program. Clinical and educational activities include participation in the Women's Health Clinic, weekly lectures, monthly CME programs focusing on specific women's health issues, and general medicine topics with emphasis on women's issues and the impact of gender on health and disease.

\section{Reason for Initiating the Program}

"The residency track of the Internal Medicine residency program was developed to enrich the training of internists with a specific interest in women's health and the impact of gender on health and disease." 


\section{Institution(s)}

University of Alabama Hospital in

Birmingham (AL)

Program Type: Residency in Women's Health

Date Established: July 1999

Number of Positions: 3 per year

Duration of Program: 3 years

Sponsored by:

Department of Internal Medicine

Co-Sponsoring Institution(s)/Department(s)

Department of Gynecology

Contact(s):

Teresa Bryan, M.D. \&

Emily Boohaker, M.D.

Co-Directors, Women's Health Track

$15303^{\text {rd }}$ Avenue South

FOT 720

Birmingham, AL 35294-3407

Telephone: (205) 934-3007

FAX: (205) 975-7797

E-mail: teresa.bryan@med.va.gov eboohake@uab.edu

\section{Eligibility Requirement(s)}

Acceptance to University of Alabama Hospital in Birmingham, Internal Medicine Residency training program is required.

\section{Required Activities}

Residents will be required to complete the following activities: 1) attend a Continuity Women's Clinic every other week, 2) participate in 3 to 4 , month long ambulatory rotations with a $50 \%$ focus in women's health, 3) participate in women's health conferences and journal clubs, and 4) complete all requirements of the UAB Internal Medicine residency program.

\section{Elective Activities}

Elective activities include women's health research projects and attendance of regional/national meetings.

\section{Special Degree(s)/Certificate(s) Offered}

None were specified.

\section{Goals of the Program}

"To provide training in primary care with an additional focus in women's health. Residents receive gender specific training to allow provision of comprehensive health care to women, in addition to a solid foundation in all traditional aspects of internal medicine."

\section{Other Program Features}

Participation in Gynecology Clinic, Breast Clinic, Osteoporosis Clinic, High Risk OB Clinic, Endocrine Clinic, STD Clinic, Continence Clinic, and other ambulatory rotations. Curriculum is very flexible and tailored to the interest and requests of each individual resident.

\section{Reason for Initiating Program}

"Our Women's Health Residency was developed to provide interested residents with additional expertise in the area of women's health." 


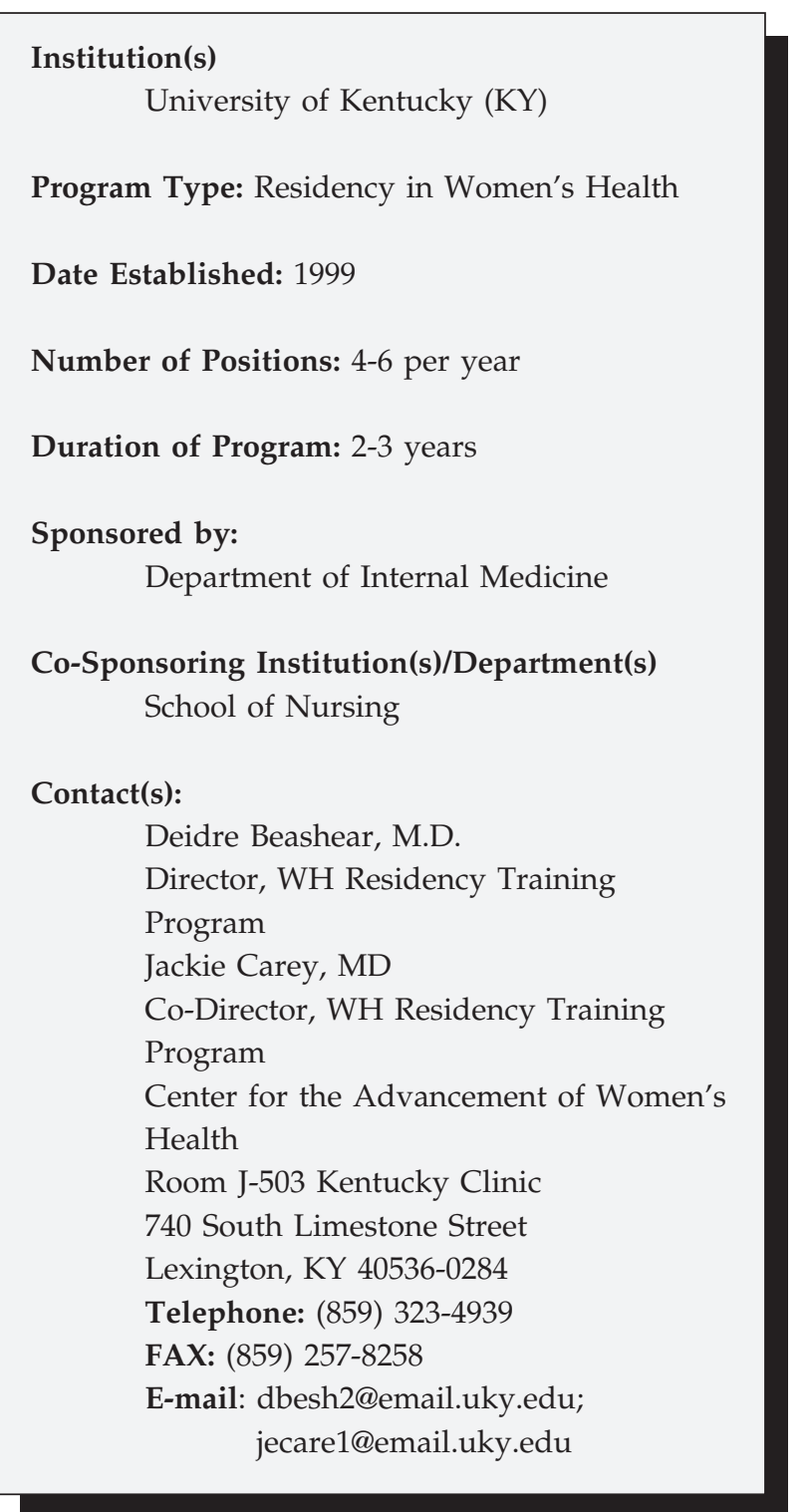
Registry designed to understand the epidemiology of symptoms and diseases as well as to increase participation of women in clinical trials.

\section{Reason for Initiating Program}

“This Women's Health track was started as part of an effort to provide specific education and clinical skills in women's health to internal medicine residents. Past surveys of both faculty and residents at our institution revealed a deficit in women's health knowledge, and a deficit of women's health topics in the traditional curriculum. Additionally, this women's health track is one facet of an expanding women's health curriculum throughout the entire medical center, as our University is the recipient of a multidisciplinary FIPSE (Fund for Improving Post-Secondary Education) grant to integrate women's health into the curriculum of health professionals." 


\section{Institution(s)}

University of Pittsburgh Medical

Center/University of Pittsburgh School of Medicine (PA)

Program Type: Residency Track in Women's Health

Date Established: June 1993

Number of Positions: 4 per year

Duration of Program: 3 years

Sponsored by:

Department of Medicine

Co-Sponsoring Institution(s)/Department(s)

Departments of Obstetrics and

Gynecology, Psychiatry, and Pediatrics

Contact(s)

Raquel Buranosky, M.D.

Assistant Professor of Medicine

Division of General Medicine

University of Pittsburgh Medical Center

Montefiore, Suite W933

200 Lothrop Street

Pittsburgh, PA 15213

Telephone: (412) 692-4891

FAX: (412) 692-4892

E-mail: buranoskyr@upmc.edu

\section{Eligibility Requirement(s)}

A medical degree is required.

\section{Required Activities}

Residents take one-month rotations in the Emergency Department at Magee Women's Hospital and a Women's Psychiatric Unit. Residents are required to rotate through the following outpatient clinics: Osteoporosis, Colposcopy, Urogynecology, Adolescent Medicine, Reproductive Endocrinology, Urgent Gynecology, Breast Disease, Menopause, and one month at the Student Health Center. They serve as medical consultants for obstetrical patients. A month of mental health was added for outpatients assessments for depression, anxiety, PTSD, etc.

\section{Elective Activities}

The program is structured as a series of electives spread throughout the three years of an Internal Medicine residency.

\section{Special Degree(s)/Certificate(s) Offered}

Residents are board eligible in Internal Medicine.

\section{Goals of the Program}

"To increase training in women's health for Internal Medicine residents."

\section{Other Program Features}

A monthly journal club allows for in-depth discussion of specific issues related to women's health.

\section{Reason for Initiating Program}

"Women's health was not adequately taught in the categorical Internal Medicine residency." 


\begin{tabular}{|c|}
\hline Institution(s) \\
\hline Virginia Commonwealth University \\
\hline Medical Center (VA) \\
\hline Program Type: Residency in Women's Health \\
\hline Date Established: June 1997 \\
\hline Number of Positions: $4-5$ per year \\
\hline Duration of Program: 3 years \\
\hline Sponsored by: \\
\hline Department of Medicine \\
\hline Contact(s) \\
\hline Kelsey E. S. Salley, M.D. \\
\hline Associate Program Director for Women's \\
\hline Health \\
\hline Department of Internal Medicine \\
\hline Maia LaVallee, M.S. \\
\hline Virginia Commonwealth University \\
\hline School of Medicine \\
\hline P.O. Box 980509 \\
\hline Richmond, VA 23298-0509 \\
\hline Telephone: (804) 828-9726 \\
\hline FAX: (804) 828-4926 \\
\hline E-mail: imea@mail2.vcu.edu \\
\hline
\end{tabular}

\section{Eligibility Requirement(s)}

A medical degree is required.

\section{Required Activities}

In addition to the required rotations and conferences in the Internal Medicine program, residents participate in outpatient continuity clinics in both Gynecology and Psychiatry. Other required activities include a one month/year in the multidisciplinary Women's Health Center, one month/year in a didactic block devoted to half-day seminars and small group discussions on primary care and women's health topics in conjunction with halfday continuity clinics, and a one-month multidisciplinary rotation in Breast Health.

\section{Elective Activities}

Residents may elect further experience, schedule permitting.

\section{Special Degree(s)/Certificate(s) Offered}

Residents are board eligible in Internal Medicine.

\section{Goals of the Program}

"To provide broad-based clinical training in Internal Medicine with a central focus on women's health promotion, disease prevention and biopsychosocial issues; to increase awareness among health care professionals regarding issues in women's health, and to promote leadership, research and education in women's health."

\section{Other Program Features}

In Bone Clinic, the use of bone densitometry and osteoporosis management are included during the outpatient month in the Women's Health Center. Other clinic experiences during this block include: Urogynecology, Rheumatology, Women's Health Physical Therapy, Gyn Oncology, Endocrine, and Fan Free Clinic. The Breast Health month is a multidisciplinary rotation in medical oncology, surgical oncology, radiation oncology, mammography, pathology, and lactation consultation. A Women's Health Journal Club meets monthly to discuss issues relevant to women's health. There is a strong mentoring component, utilizing expert women faculty as discussants and lecturers. The program also features an orientation for incoming interns to refine their skills in pelvic and breast exams. A CME Women's Health Conference is held annually and elective rotations include Student Health and Adolescent Medicine.

\section{Reason for Initiating Program}

To provide comprehensive multidisciplinary training for Internal Medicine residents with interest in the area of Women's Health, whether they are planning a career in General Medicine or subspecialty training. 


\section{Fellowships in Women's Health}




\begin{tabular}{|c|}
\hline Institution(s) \\
\hline Aurora Women's Pavilion, West Allis \\
\hline Memorial Hospital, Milwaukee, WI \\
\hline Program Type: Women's Health Fellowship \\
\hline Date Established: July 1, 2006 \\
\hline Number of Positions: 1 per year \\
\hline Duration of Program: 1 year \\
\hline Sponsored by: \\
\hline Aurora Health Care, Milwauke, WI \\
\hline Co-Sponsoring Institution(s)/Department(s) \\
\hline Department of Family Medicine and \\
\hline Aurora Women's Pavilion \\
\hline Contact(s) \\
\hline Kayt Klein Havens, M.D. \\
\hline Co-Director Aurora Women's Health \\
\hline Fellowship \\
\hline Aurora Women's Pavilion \\
\hline 8901 W. Lincoln Ave. \\
\hline West Alllis, Wisconsin 53227 \\
\hline Telephone: 414-329-5634 \\
\hline E-mail: kathryn.havens.md@aurora.org \\
\hline Laurie Bailey, MD \\
\hline Co-Director Aurora Women's Health \\
\hline Fellowship \& \\
\hline Clinical Medical Director Aurora \\
\hline Women's Pavilion \\
\hline Center for Optimal Health and Wellness \\
\hline 8901 W. Lincoln Ave. \\
\hline West Allis, WI 53227 \\
\hline Telephone: 414-329-5936 \\
\hline Fax: 414-329-5919 \\
\hline
\end{tabular}

munity involvement is highly encouraged. If interested, research opportunities do exist but are not munity involvement is highly encouraged. If interested, research opportunities do exist but are not a requirement of the fellowship.

\section{Reason for Initiating Program}

"The fellowship was developed to provide additional opportunities and training in the field of Women's Health to those physicians who have in interest in providing high quality, state of the art care to women. The current Co-Director, Dr. Bailey, started this fellowship in response to her own interest in pursuing more specialized training in Women's Health and was the first Aurora Women's Health Fellow."

\section{Eligibility Requirement(s)}

Board Eligibility in Family Medicine, Internal Medicine, Ob-Gyn, with completion of residency in a United States licensed program.

\section{Required Activities}

The fellow will gain clinical experience in the following sub-specialty areas: breast health, cardiology, general gynecology, gynecologic oncology, behavioral medicine, urogynecology, sexuality/sexual dysfunction, cancer survivorship and bone health. In addition it is expected that the fellow will maintain a small continuity clinic in their specialty 2 half days per week as well as staff residents 2 half days per month.

\section{Elective Activities}

Women's sports medicine, Dermatology, GI, Sexual and Domestic Abuse, Endocrine (osteoporosis, PCOS focus), and spine care.

\section{Special Degree(s)/Certificate(s) Offered}

Certificate of fellowship completion. Fellow is encouraged to become a NAMS Certified Menopause Practitioner and is given time for adequate preparation.

\section{Goals of the Program}

"To provide the practitioner with a special interest in the field of women's health the opportunity to gain expertise in the clinical, educational, research, and administrative aspects of women's health."

\section{Other Program Features}

There is a great deal of flexibility for the fellow to determine her own rotations and interests throughout the year. Opportunities include both longitudinal and rotational clinical experiences. In addition, the fellow is encouraged to participate in program development and other administrative experiences, as they are available. Com- 


Institution(s)
Boston University School of Medicine
Program Type: Women's Health Fellowship, a
concentration within the BU General
Internal/Family Medicine Fellowship
program
Date Established: 1994
Number of Positions: 1-2 per year
Duration of Program: 2 years
Sponsored by:
Department of Medicine
Fontact(s)
Karen M Freund M.D., M.P.H.
Professor of Medicine and Epidemiology
Co-Director of the Women's Health
Fellowship
Bo1 Massachusetts Avenue, Suite 470
Volephone:
Boston Medical Center

Special Degree(s)/Certificate(s) Offered

\section{Eligibility Requirement(s)}

Board eligible/board certified in Internal Medicine (or equivalent) is required.

\section{Required Activities}

The Women's Health Fellows gain experience in research, medical education, administration, and clinical care in women's health. Within the first year, most fellows develop a focused expertise within one these areas, while developing knowledge and skills in all areas. There are a number of required and elective activities to achieve these goals. Fellows take courses at Boston University School of Public Health with a focus on Biostatistics, Epidemiology, and Health Services. They maintain a continuity ambulatory practice at the Women's Health Group at Boston Medical Center and the Women Veterans Health Center at the VA Boston Healthcare System. Career development seminars in clinical research, medical education, administration, and management are core elements of the fellowship. Fellows must develop at least one (preferably two) research projects on women's health with guidance from faculty preceptors, with one project addressing the health of women veterans.

\section{Elective Activities}

There is an opportunity for additional clinical work in Breast Health, Obstetrics and Gynecology, Osteoporosis, Cardiology, and Mental Health. Past trainees have received training in percutaneous needle biopsy of the breast and certification in interpretation of bone mineral density. Fellows can participate in the institution's K30 CREST (Clinical Research Training program).

Fellows are eligible for course work at Boston University School of Public Health leading to a Master of Science in Epidemiology or Health Services. They may also complete additional rotations and be eligible for board certification in Preventive Medicine.

\section{Goals of the Program}

Our program is based upon a comprehensive model of women's health, with a focus on addressing health disparities in women. The goal of our program is to train future leaders in women's health research, teaching, health administration, and policy.

\section{Other Program Features}

The fellowship is integrated into activities at the Boston University Center of Excellence in Women's Health.

\section{Reason for Initiating Program}

The fellowship in women's health is a separate track within the General Internal Medicine/Family Medicine fellowship and provides fellows with a host of resources from both Boston University and the VA Boston Healthcare System. This fellowship track began and continues with funding through the Department of Veterans Affairs. 


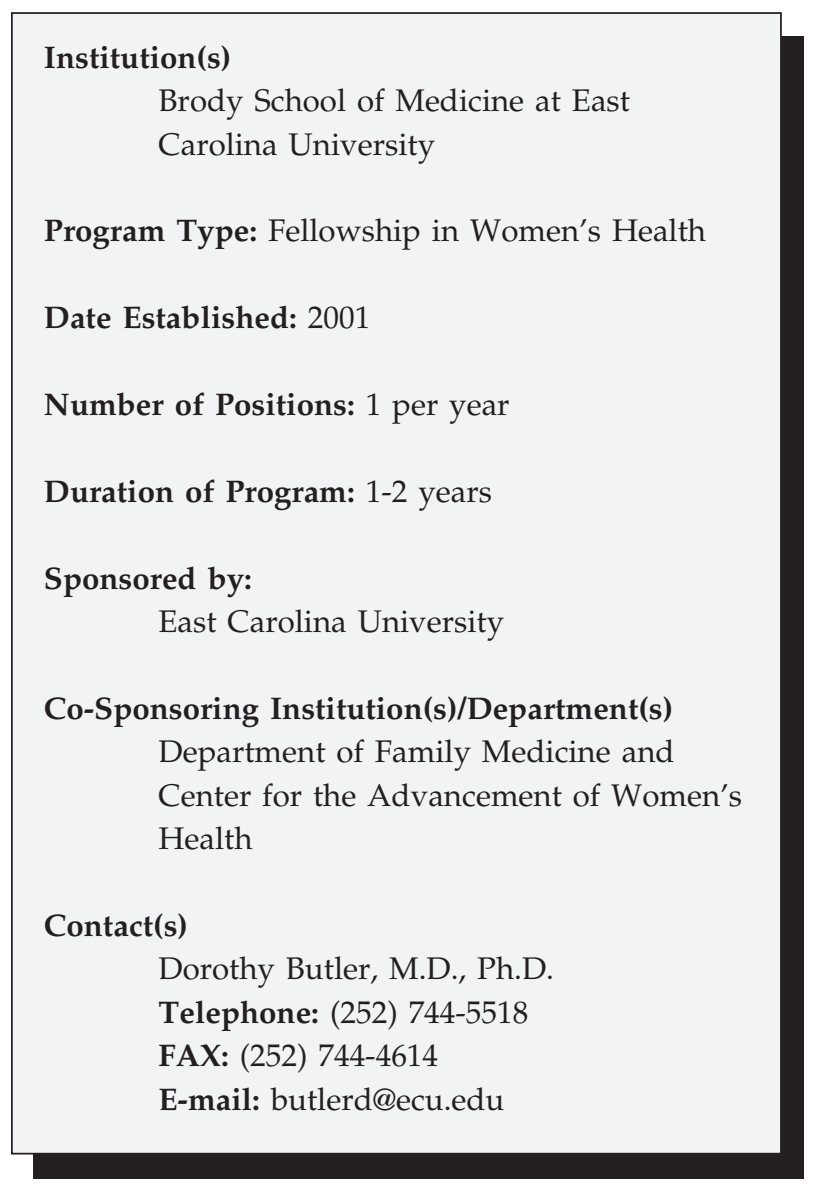

Eligibility Requirement(s)

Board eligible/board certified graduate of an ACGME-approved family practice or internal medicine residency program.

\section{Required Activities}

Breast Clinic (3 months); Obstetrical Ultrasound (Longitudinal); Faculty Development Course; Skills Clinic; Maternity Care Clinic (OB Fellow only-Longitudinal); Prenatal Care Clinic (OB Fellow only); Labor and Delivery call is one evening per week and one weekend per month with Family Medicine Attending Physician Supervision; one Grand Rounds presentation during one-year fellowship; Participation in teaching activities in the resident curriculum; Creative activity encouraged.

\section{Elective Activities}

Maternal Fetal Medicine; Chronic Pelvic Pain Clinic; Behavioral Medicine; Lactation Consultation; Nutrition; Other Specialty of Choice (Will be arranged by fellowhip director upon request of fellow)

\section{Special Degree(s)/Certificate(s) Offered}

Certificate offered.

\section{Goals of the Program}

"To support training for primary care physicians in comprehensive and coordinated women's health primary care and formalizing women's health training in the attitudes, knowledge, and skills required to respond to the special health care needs of women."

\section{Other Program Features}

Concentration could include clinical strategies in curriculum development or clinical teaching. Clinical appointments are held in the Department of Family Medicine.

\section{Reason for Initiating Program}

"To support the mission of the Brody School of Medicine at East Carolina University to improve the health care of eastern North Carolina through the advancement of medical education and research. The fellowship program seeks to improve the health professional training in primary care of women by establishing academic and community leaders in women's health care." 


\begin{tabular}{|c|}
\hline Institution(s) \\
\hline Cedars-Sinai Medical Center \\
\hline $\begin{array}{c}\text { Program Type: Fellowship in Women's Heart } \\
\text { Disease and Health }\end{array}$ \\
\hline Date Established: 2002 \\
\hline Number of Positions: 1 per year \\
\hline Duration of Program: 1 year \\
\hline Sponsored by: \\
\hline $\begin{array}{l}\text { Women's Heart Center, Cedars-Sinai } \\
\text { Medical Center }\end{array}$ \\
\hline $\begin{array}{l}\text { Contact(s) } \\
\text { Noel Bairey Merz, M.D. } \\
\text { Medical Director, Women's Health } \\
\text { Program } \\
\text { Women's Guild Chair in Women's } \\
\text { Health } \\
\text { Cedars-Sinai Medical Center } \\
\text { Mark Goodson Building Suite } 600 \\
\text { Los Angeles, CA 90048 } \\
\text { Telephone: (310) 423-9680 } \\
\text { Fax: (310) 423-9681 } \\
\text { E-mail: merz@cshs.org }\end{array}$ \\
\hline
\end{tabular}

\section{Eligibility Requirement(s)}

Completion of a residency in internal medicine, OB-GYN, or family medicine.

\section{Required Activities}

Under the direction of Dr. Bairey Merz, the Fellow will work with Dr. Bairey Merz in her pioneering research in the prevention and diagnosis of heart disease in women. Specifically, the Fellow will participate and facilitate the clinical aspects of the ongoing research directed at improved understanding of the gender differences in heart disease, in order to translate these research findings into improved heart disease care for women.

\section{Elective Activities}

1. Didactic and Clinical Core Women's Health Curriculum-six core rotations in 1) Bone HealthEndocrinology, 2) Reproductive Health-Office $\mathrm{Ob} / \mathrm{Gyn}, 3)$ Mental Health-Depression/Anxiety / Eating Disorder Clinic, 4) Preventive Health, 5) Breast Health-Radiology, 6) Elective, e.g. but not limited to Rheumatology, Cardiology, Alternative and Complementary Medicine, Uro-Gynecology/pelvic floor voiding, Adolescent Medicine, Office-based GYN Procedures, Medical High-risk Pregnancy, Chronic Pelvic Pain 2. Weekly ongoing continuity clinics in Office Gynecology and Women's Primary Care. 3. Academic Programs-e.g. arrange weekly-monthly conferences, journal club, Colloqui and quarterly Interdisciplinary Grand Rounds on Women's Health Topics. 4. Tutorials with desginated mentor(s) 5. Career Development Seminars 6. Many options are available through UCLA and USC systems

\section{Special Degree(s)/Certificate(s) Offered}

Fellows are eligible for course work at UCLA leading to a Master of Public Health degree.

\section{Goals of the Program}

1. To provide focused training in clinical and translational research with regard to heart disease in women.

2. To provide training in the comprehensive care of women across the lifespan.

3. To train practitioners in research, teaching, health administration and policy in women's health. 4. To respond to the needs of individual residents, fellows, faculty and voluntary staff regarding women's health in the medical institution and community. 


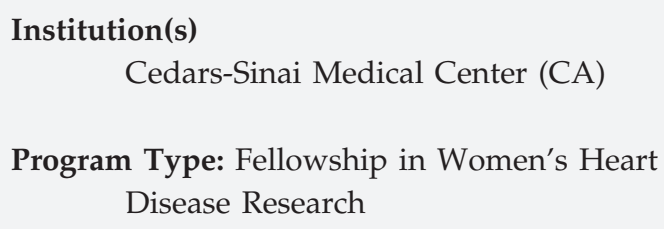

Program Type: Fellowship in Women's Heart Disease Research

Date Established: 2007

Number of Positions: 1 per year

Duration of Program: 1 year

Sponsored by:

The Edythe L. Broad Cardiology

Research Fellowship (\#217243)

\section{Contact(s)}

Noel Bairey Merz, M.D.

Medical Director, Women's Health

Program

Women's Guild Chair in Women's

Health

Cedars-Sinai Medical Center

Mark Goodson Building Suite 600

Los Angeles, CA 90048

Telephone: (310) 423-9680

Fax: (310) 423-9681

E-mail: merz@cshs.org

\section{Eligibility Requirement(s)}

Completion of a post-graduate training in medicine, epidemiology, biostatistics, health administration or biomedical sciences.

\section{Required Activities}

Under the direction of Dr. Bairey Merz, the Fellow will work with Dr. Bairey Merz in her pioneering research in the prevention, diagnosis and treatment of heart disease in women. Specifically, the Fellow will participate and facilitate the basic, clinical and translational aspects of the ongoing research directed at improved understanding of the gender differences in heart disease, in order to translate these research findings into improved heart disease care for women.

\section{Elective Activities}

1. Academic Programs-e.g. arrange weeklymonthly conferences, journal club, Colloqui and quarterly training in research. 2. Tutorials with desginated mentor(s) 3. Career Development Seminars 4. Many options are available through UCLA and USC systems

\section{Special Degree(s)/Certificate(s) Offered}

Fellows are eligible for course work at UCLA leading to a Master of Public Health degree.

\section{Goals of the Program}

1. To provide focused training in basic, clinical and translational research with regard to heart disease in women.

2. To train practitioners in research, teaching, health administration and policy in women's heart research.

3. To respond to need of individual residents, fellows, faculty and voluntary staff regarding women's health research in the medical institution and community 


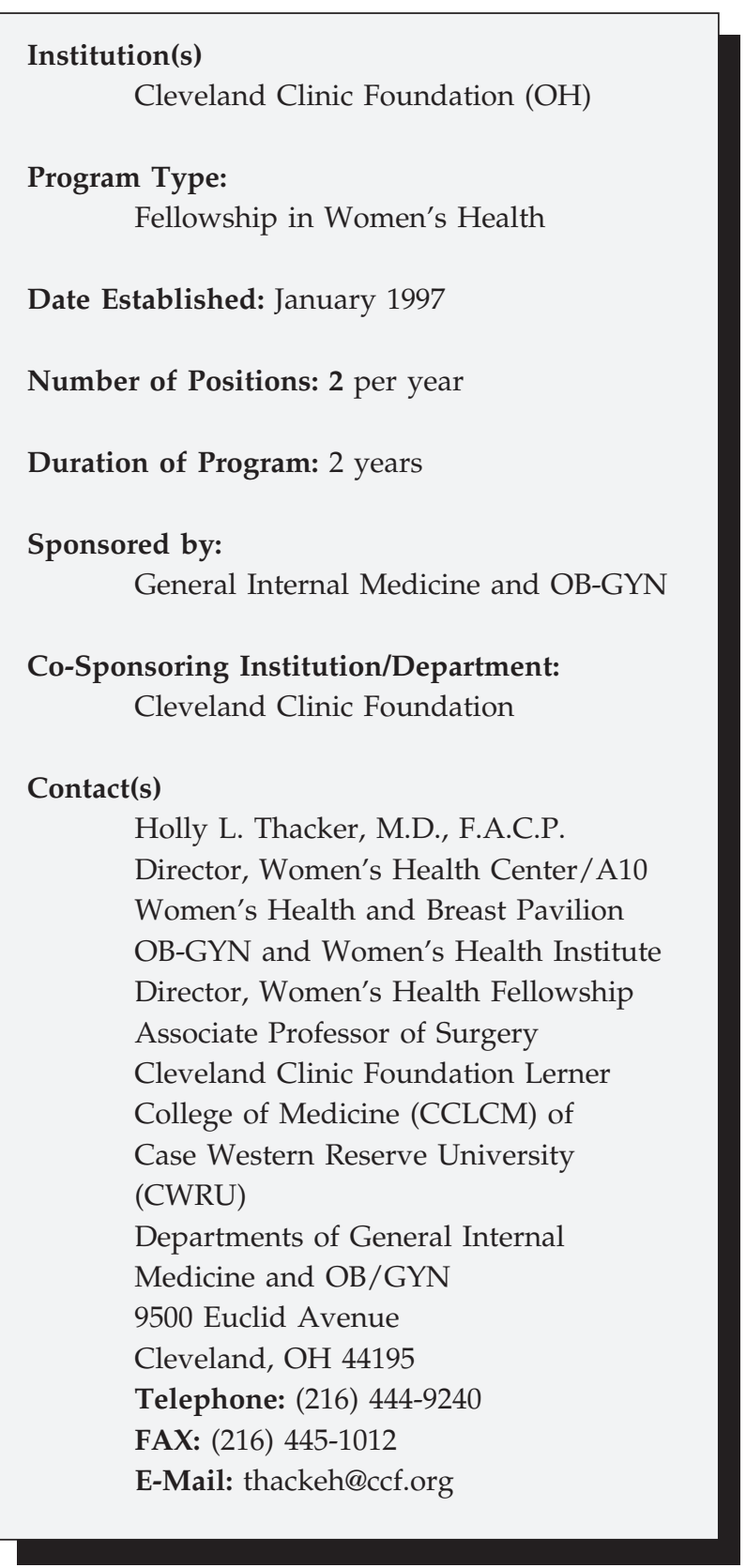

\section{Eligibility Requirement(s)}

Completion of residency in Internal Medicine or Family Medicine is required.

See article in Journal of Women's Health Sept 2007

\section{Required Activities}

Training and hands-on experience in research with a view to starting a clinician scholar career are emphasized. The fellowship has a minimum of six months of clinical, collaborative, inter-disciplinary rotations including but not limited to: Women's Health Center at the Women's Health and Breast Pavilion, Pelvic Floor/Voiding Center, Metabolic and Osteoporosis Bone Center, Breast Center, Cardiology Prevention Clinic, Menopause Clinic, Chronic Pelvic Pain Clinic, and Women's Health Psychiatry. Completion of a project on a gender-based topic is required.

\section{Elective Activities}

Multiple offerings throughout the entire Cleveland Clinic Health System, as well as our geographic Women's Health Center.

\section{Special Degree(s)/Certificate(s) Offered}

A certificate of training as a Clinical Scholar specializing in Women's Health from the Cleveland Clinic Foundation is offered. Fellows have the option to earn a Master of Public Health degree.

\section{Goals of the Program}

"To educate future clinicians, clinician-educators, and researchers in the areas of prevention and treatment of diseases unique or more prevalent in women."

\section{Other Program Features}

Fellows will receive extensive education in women's health practice management, experiential training opportunities, and community outreach as part of the Cleveland Clinic's effort to provide clinically effective, caring, and cost-conscious medical care promoting health and wellness. Skills in research and leadership effectiveness are formally emphasized.

\section{Reason for Initiating Program}

"The fellowship was developed out of the interest of the faculty in sharing Cleveland Clinic's available resources for the exploration and study of the gender-related aspects of illness." 


Institution(s)
Durham Veterans Affairs Medical Center
Duke University School of Medicine
Program Type: Fellowship in Women's Health
Date Established: July 1994
Number of Positions: 1 per year
Duration of Program: 2 years
Sponsored by:
Department of Medicine and Division of
General Internal Medicine
Telephone: (919) 668-2127
FAX: (919) 668-1300
E-mail: Basti001@mc.duke.edu
Co-Sponsoring Institution(s)/Department(s)
Departments of Obstetrics and
Gynecology, Psychiatry, and Surgery
Dorich Bastian, M.D., M.P.H.
Dodical Director Women's Health
Contact(s)

\section{Other Program Features}

The fellowship program is under the direction of Dr. David Edelman, who also directs fellowships in General Internal Medicine and Health Services Research. All fellows share office space and take classes together, which creates a collaborative environment.

\section{Reason for Initiating Program}

"This fellowship program was awarded as the result of a competitive application process through the Department of Veterans Affairs. The establishment of a women veterans comprehensive health center allows the fellowship to be multidisciplinary in clinical practice and research opportunities."

\section{Eligibility Requirement(s)}

A United States citizen who is board eligible in Internal Medicine, Obstetrics and Gynecology, Psychiatry or Surgery and has good clinical skills and an interest in academic medicine is eligible.

\section{Required Activities}

Seventy-five percent of the fellow's time is devoted to research, including master's level classes in epidemiology and statistics, teaching residents, and $25 \%$ to clinical care. A fellow maintains a two half-day long-term clinic.

\section{Elective Activities}

Examples of courses available in the Duke University Biometry program are: Introduction to Statistical Methods, Ethical Issues in Clinical Research, Principles of Clinical Research, Health Economics in Clinical Research, Clinical Research Seminar, Health Services Research and Psychometrics and Reliability.

\section{Special Degree(s)/Certificate(s) Offered}

With appropriate course work at Duke University Biometry Program, a fellow is eligible for a Master of Health Sciences degree.

\section{Goals of the Program}

"To train academic women's health researchers with an emphasis on clinical research and house staff education and to train Department of Veterans Affairs physicians to excel in women's health." 


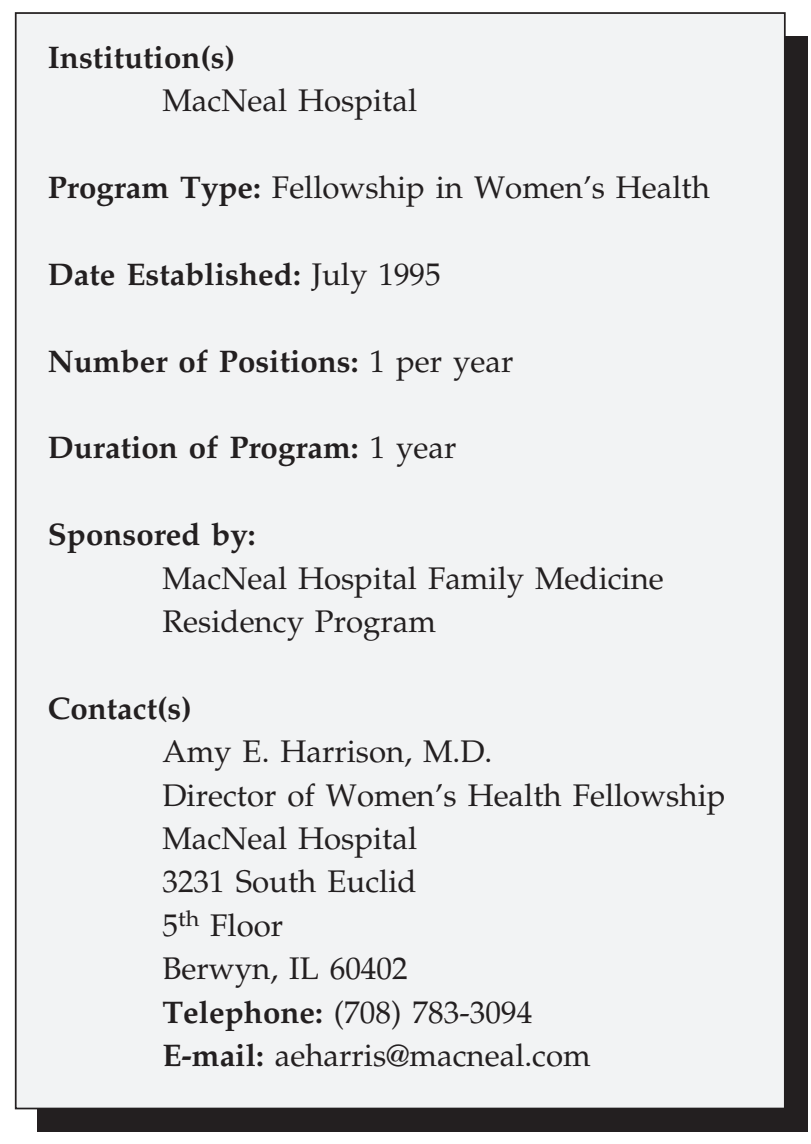

\section{Eligibility Requirement(s)}

Completion of a Family Practice residency program (preferred) or an Internal Medicine Residency is required.

\section{Required Activities}

Longitudinal care of patients in the Family Medicine Center. A scholarly project in an area of women's health is also required.

\section{Elective Activities}

This program is very flexible, and allows its fellows to do electives in any area of women's health.

\section{Special Degree(s)/Certificate(s) Offered}

None are offered.

\section{Goals of the Program}

"To provide advanced training in the broad spectrum of women's health."

\section{Other Program Features}

Information was not provided.

\section{Reason for Initiating Program}

"This fellowship was started to provide advanced training in women's health. It is designed for clinicians interested in obtaining advanced training in the broad spectrum of women's health." 


Institution(s)
Marshall University School of Medicine
Program Type: Fellowship in Women's Health
Date Established: 1994
Number of Positions: 1 per year
Duration of Program: 1 year
Sponsored by:
Department of Family and Community
Health
Co-Sponsoring Institution(s)/Department(s)
Cabell Huntington Hospital
Felephone: (304) $697-7000$
E-mail: savory@marshall.edu
Huntington, WV 25701
Linda Savory, M.D.
Marshall University School of Medicine
1305 Elm St.
Contact(s)

patient treatment of gynecological disease while maintaining a holistic approach as a primary care provider."

\section{Other Program Features}

The fellow will not only provide medical care but will also become familiar with problems such as single parenting, domestic violence, adolescent health issues and sexual abuse. The program offers a great deal of flexibility.

\section{Reason for Initiating Program}

"The fellowship was started by a Family Practice resident with a special interest in women's health. She desired additional training and developed the goals and curriculum with the Department Chair." 


Institution(s)
Mayo Clinic College of Medicine (MN)
Program Type: Fellowship in Women's Health
Date Established: 1997
Number of Positions: 2 per year
Duration of Program: 2 years
Sponsored by:
Department of Medicine
Contact(s)
Deborah Rhodes, M.D.
Women's Health Fellowship Program
Director
Mayo Clinic School of Graduate Medical
Education
200 First Street SW
Rochester, MN 55905
Telephone: (507) $284-2220$
FAX: (507) 284-0999
E-modes.deborah@mayo.edu

\section{Eligibility Requirement(s)}

Medical degree and residency (internal medicine, family medicine, or obstetrics-gynecology) are required.

\section{Required Activities}

The Women's Health Fellowship combines training in clinical research with required and elective clinical rotations in women's health.

Fellows complete the Clinical Research Training Program or a Master of Science in Clinical Research. This includes didactic training in statistical methods, clinical epidemiology, protocol development, scientific writing, critical appraisal of the medical literature and leadership skills. Fellows are expected to design, conduct, analyze, and submit for publication a research thesis under the direction of a multi-disciplinary group of mentors chosen according to the fellow's research interests.

Required clinical rotations include: Women's Health Clinic (focused on hormonal and sexual concerns), Medical Gynecology, Maternal-Fetal Medicine, Urogynecology, Bone Clinic, Nutrition Clinic, General Endocrinology, Psychiatry, Breast Diagnostic and Cancer Clinic, Breast Imaging, and Women's Cardiovascular Clinic.

Fellows organize a large monthly journal club attended by students and faculty interested in women's health. Fellows participate in a career development series.

\section{Elective Activities}

Psychiatry, Dermatology, Headache Clinic, Nicotine Dependence, Pain Clinic, Rheumatology, Spine Clinic, and any other clinics relevant to the fellow's area/s of interest.

\section{Special Degree(s)/Certificate(s) Offered}

Fellows must complete either a Certificate in Clinical Research or a Masters of Science in Clinical Research.

\section{Goals of the Program}

The Women's Health Fellowship at Mayo Clinic combines interdisciplinary training in the prevention and treatment of diseases prevalent in women with immersion in the principles and practice of clinical research.

\section{Other Program Features}

The fellows meet weekly with the fellowship director for research proposal progress reports and career planning.

\section{Reason for Initiating Program}

To develop leaders in the evolving field of Women's Health and to improve health care outcomes for women. 


\section{Institution(s)}

Pittsburgh Veterans Affairs Medical Center/University of Pittsburgh School of Medicine

Program Type: Fellowship in Women's Health

Date Established: June 1995

Number of Positions: 1 per year

Duration of Program: 2 years

Sponsored by:

Department of Medicine and School of

Public Health, University of Pittsburgh

Co-Sponsoring Institution(s)/Department(s)

Department of Obstetrics and

Gynecology

Contact(s)

Melissa McNeil, M.D., M.P.H.

Chief, Section of Women's Health

Division of General Medicine

UPMC Montefiore, Suite W933

200 Lothrop St.

Pittsburgh, PA 15213

Telephone: (412) 692-4891

FAX: (412) 692-4892

E-mail: mcneilma@upmc.edu

\section{Eligibility Requirement(s)}

Completion of an Internal Medicine, Family Practice, Surgery, Obstetrics and Gynecology, or Psychiatry residency is required.

\section{Required Activities}

Seventy-five percent of a fellow's time is devoted to research, which includes master's level classes in Epidemiology, and 25\% to clinical care.

\section{Elective Activities}

Fellows can rotate through community health centers (rape centers, battered women shelters) and clinics, which focus on Sexually Transmitted Diseases, Colposcopy, Urogynecology, and Pregnancy Termination.

\section{Special Degree(s)/Certificate(s) Offered}

Fellows are eligible for course work at the University of Pittsburgh leading to a Master of Public Health degree and a certificate in Women's Health Epidemiology.

\section{Goals of the Program}

"To train academic physicians with interests in research and education."

\section{Other Program Features}

In addition to being closely allied with the fellowship programs in General Medicine, this fellowship is affiliated with the Magee National Center of Excellence for Women's Health.

\section{Reason for Initiating Program}

"To expand existing teaching and research programs and the General Medicine fellowship." 
Portland Veterans Affairs Medical Center Oregon Health \& Science University

Program Type: Fellowship in Women's Health

Date Established: June 1994

Number of Positions: 1-2 per year

Duration of Program: 2 years

Sponsored by:

Department of Medical Services

Co-Sponsoring Institution(s)/Department(s)

Oregon Health and Science University

Contact(s)

Linda Humphrey, M.D., M.P.H.

Director of Women's Health Fellowship

Portland Veterans Affairs Medical

Center

3781 SW US Veterans Hospital Road

Portland, OR 97207

Telephone: (503) 220-8262 x-57176

FAX: (503) 721-7807

E-mail: humphrey@ohsu.edu

\section{Institution(s)}

\section{Eligibility Requirement(s)}

Completion of a residency in Internal Medicine, Surgery, Psychiatry, Obstetrics and Gynecology, or Family Medicine is required.

\section{Required Activities}

Seventy-five percent of the program is devoted to research and teaching and $25 \%$ is devoted to clinical activities.

\section{Elective Activities}

The following clinics are available: Breast, Psychiatry, Domestic Violence, Adolescent Medicine, Gynecology, Urogynecology, Osteoporosis, Endocrinology, and Behavioral Medicine.

\section{Special Degree(s)/Certificate(s) Offered}

An optional third year is available based upon individual fellowship goals. Master of Public Health degrees and Human Investigation Program (HIP) certificates are also available.

\section{Goals of the Program}

"To train individuals for an academic career which includes research and teaching in women's health."

\section{Other Program Features}

"Our program is closely allied with fellowships in Hospital Medicine, General Internal Medicine, Informatics, and Geriatrics. We have a strong relationship with OHSU's AHRQ-supported Evidencebased Practice Center."

\section{Reason for Initiating Program}

"Our institution, in conjunction with the Oregon Health Sciences University, has the components to provide excellent training in women's health, research methodology, and education." 
Institution(s)

San Francisco Veterans Affairs Medical Center/University of California at San

Francisco School of Medicine

Program Type: Fellowship in Clinical Research Methods with a focus on Women's Health

Date Established: July 1995

Number of Positions: 2 per year

Duration of Program: 2 years

Sponsored by:

Department of Medicine

Co-Sponsoring Institution(s)/Department(s)

Departments of Epidemiology, Obstetrics and Gynecology, Psychiatry, and Surgery

\section{Contact(s)}

Deborah Grady, M.D., M.P.H.

Professor of Medicine

VA Medical Center (111A1)

4150 Clement Street

San Francisco, CA 94121

Telephone: (415) 750-2093

FAX: (415) 379-5573

Email: Deborah.Grady@ucsf.edu

\section{Eligibility Requirement(s)}

Completion of an accredited and demonstration of clinical excellence, potential research success and productivity are required.

\section{Required Activities}

Completion of the 2-year UCSF Masters in Clinical Research is required. Fellows are involved with clinical and research issues in women's health and spend approximately $25 \%$ of their time practicing clinical care.

\section{Elective Activities}

Information was not provided.

\section{Special Degree(s)/Certificate(s) Offered}

Master's in Clinical Research at the University of California, San Francisco.

\section{Goals of the Program}

"To train academic physicians to be clinical researchers in areas of women's health."

\section{Other Program Features}

Information was not provided.

\section{Reason for Initiating Program}

"To provide the multidisciplinary skills outlined above and to bridge the gaps between the specialties that have traditionally divided women's health care and research." 


Institution(s)
UCSF Women's Health Clinical Research
Center
Program Type: Fellowship in Women's Health
Date Established: 2002
Number of Positions: 2 per year
Duration of Program: 2 years
Sponsored by:
Departments of Obstetrics and
Gynecology and Epidemiology and
Biostatistics
Telephone: (415) 353-9751
FAX: (415) 353-9790
E-mail: brownj@obgyn.ucsf.edu
Fellowship website: www.whcrc.ucsf.edu
Jeanette S. Brown, M.D.
Director
UCSF Women's Health Clinical Research
Fellowship
San Francisco, CA 9415

\section{Reason for Initiating Program}

"This fellowship program builds on the research success of UCSF, the institution's commitment to women's health, and the availability of an extensive array of ongoing research projects to develop a cadre of well-trained clinical researchers in women's health."

\section{Eligibility Requirement(s)}

Medical degree and residency are required

\section{Required Activities}

Completion of the Advanced Training in Clinical Research in the first year and completion of research and writing projects in the second year. For complete details, please visit http://www. epibiostat.ucsf.edu.

\section{Elective Activities}

For complete details, please visit http://www. epibiostat.ucsf.edu.

\section{Special Degree(s)/Certificates(s) Offered}

Master's Degree in Clinical Research. For complete details, please visit http://www.epibiostat. ucsf.edu.

\section{Goals of the Program}

"To develop a cadre of well-trained clinical researchers in women's health."

\section{Other Program Features}

At the start of the 2 year program, fellows and senior mentors will develop a training plan tailored to the background and interests of each fellow and the resources available at UCSF. Fellows are expected to develop content and methodologic expertise, strong communications skills, and experience and skill in building and leading teams. 


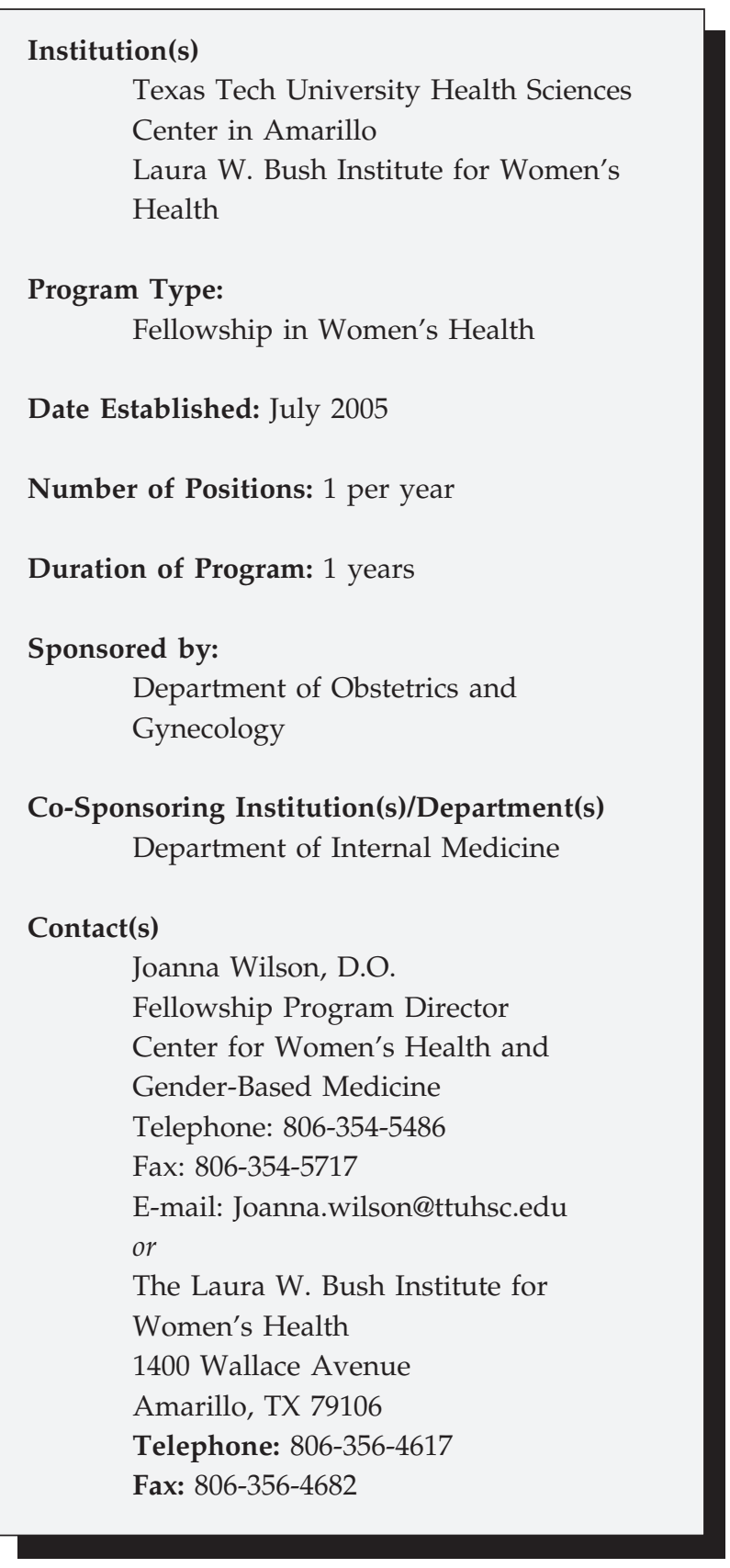
rounded fellowship clinical experience. Our beautiful new Center for Women's Health and Gender-Based Medicine provides a comfortable and pleasant work environment.

Under the guidance of a research mentor and with provided funding, each Women's Health Fellow is responsible for designing and implementing a clinical research project, and for presenting and publishing the results of this project. The Women's Health Fellow's original research project is completed during the fellow's protected research time. In addition to core and elective rotations, the fellow participates in a weekly one-onone tutorial session focusing on 12 key WH clinical topics. The fellow may also work with a consultant on public speaking techniques, PowerPoint, and presentation skills.

\section{Reason for Initiating Program}

The Laura W. Bush Women's Health Research Institute sponsors the TTUHSC WH fellowship program. Our fellowship was designed to promote clinical excellence and to prepare an individual for success in a clinical and/or academic career in Women's Health. 


\author{
Institution(s) \\ Texas Tech University Health Sciences \\ Center-El Paso \\ Laura W. Bush Institute for Women's \\ Health
}

Program Type:

Fellowship in Women's Health

Date Established: July 2009

Number of Positions: 1 per year

Duration of Program: 2 years

Sponsored by:

Department of Obstetrics and

Gynecology

Co-Sponsoring Institution(s)/Department(s)

Departments of Family Medicine \&

Internal Medicine

Contact(s)

Bahij Nuwayhid, MD, PhD

Professor \& Regional Chair

4800 Alberta Avenue

TTUHSC-El Paso

Department of OB/GYN

El Paso, TX 79905

Telephone: $915-545-9776$

Fax: 915-545-6732

Email: Bahij.nuwayhid@ttuhsc.edu

Yvette Quintana-Chavez

Women's Health Administrator

4800 Alberta Avenue

El Paso, TX 79905

Telephone: 915-545-6611 ext. 290

Fax: 915-545-6946

Email: yvette.quintanachavez@ttuhsc.edu

\section{Eligibility Requirement(s)}

Applicants must be board-eligible or board-certified in Internal Medicine, Obstetrics and Gynecology, or Family Medicine.

\section{Required Activities}

Continuity Clinics in Family Medicine, Gynecology, General

Internal Medicine and Adolescent Health. Rotations in Metabolic Bone Disease. Geriatrics, Breast Health, and Cardiology. At least one clinical research project should be completed and be of publication quality.

\section{Elective Activities}

Psychiatry; Advanced OB/GYN Ultrasound; High Risk Obstetrics \& Diabetes; Infertility; GYN Oncology; Urogynecology; Endocrinology. Procedural Competency: Endometrial Biopsy; Colposcopy, Laser, LEEP and Cervical Biopsies; Cystometrics; Saline enhanced sono; Office gynecology procedures; Sonography-Fetal biometry, Amniotic Fluid Index.

\section{Special Degree(s)/Certificate(s) Offered}

Certified NAMS menopause practitioner, Certified bone densitometry ISCD, Certificate of Completion - Texas Medical Board \& Texas Tech University HSC, Eligibility for MPH Degree

\section{Goals of the Program}

Increase clinical competence for physicians interested in $1^{\circ}$ care for women. Provide trainees with needed clinical and research skills to pursue academic careers centered on Women's Health. Prepare trainees to assume leadership positions on women's health in their communities.

\section{Other Program Features:}

El Paso is a U.S.-Mexico border community that is ethnically diversified but with a Hispanic majority. Women's health issues that predominate include high rates of teen pregnancies, sexually transmitted diseases, hypertension and other cardiovascular diseases. Due to lack of adequate cancer screening, advanced stage breast and gynecological cancers are common. Several community and partnership clinics serve the needs of the community and the university Hospital and clinics serve as a referral center. As a result, we have a large number of patients in the community partnership and specialty clinics.

- Opportunity to work in Community Partnership Clinics in a culturally sensitive environment.

- Opportunity to pursue clinical research relevant to Hispanic populations and border communities.

- Opportunity to learn medical Spanish.

- Complete a Faculty Development Course

- Opportunity to take epidemiology, biostatistics and behavioral science courses that lead to MPH eligibility.

- Weekly meetings with clinical and research mentors to review clinical topics of interest or research design/statistical analysis.

\section{Reason for Initiating Program:}

El Paso, Texas and Juarez, Mexico are two sister cities on the U.S. - Mexico border with a total population of more than 2.5 million. The population is medically underserved and women's health issues that predominate, necessitating development of clinical models of health care that meet the health literacy, language and cultural sensitivity needs of women. Additionally, research on ethnic and gender differences and border community health issues are needed in order to lower the incidence of chronic diseases.

The Centers of Excellence in Obesity/Diabetes and Cancer at the Paul L. Foster School of Medicine, our unique geographical location and the enthusiastic support of the sponsoring and collaborating clinical departments and Dean's office allow us to have a successful and unique Women's Health Fellowship Program. 


Institution(s)
University of California, Davis School of
Medicine
Program Type: Fellowship in Women's Health
Date Established: 2004
Number of Positions: 2 per year
Duration of Program: 2 years
Co-Sponsoring Institution(s)/Department(s)
UC Davis Health System/Internal
Medicine, Obstetrics \& Gynecology
Contact(s)
Richard Sweet, M.D.
Director-Women's Center for Health
Program
4860 Y Street, Suite 2500
Sacramento, CA 95817
Telephone: (916) $734-6670$

\section{Eligibility Requirement(s)}

Medical degree and residency (internal medicine, family medicine, obstetrics-gynecology) are required.

\section{Required Activities}

Completion of the Mentored Clinical Research Training Program with obtainment of a Certificate in Clinical Research Studies or a Masters of Advanced Studies in Clinical Research is required. The certificate or masters is completed during the fellowship.

Required clinical activities during the two-year fellowship include Women's Assessment Center, Breast Center, Osteoporosis, Women's Cardiovascular Clinic, Endocrinology, Gynecology, Pelvic Floor and Incontinence Center, Weight Management, and Women's Mental Health.

\section{Elective Activities}

Elective activities include rotations in dermatology, rheumatology and gastoenterology; and career development seminars

\section{Special Degree(s)/Certificate(s) Offered}

Master's of Advanced Studies in Clinical Research/Certificate in Clinical Research Studies is offered.

\section{Goals of the Program}

"To develop a cadre of well-trained clinicians and clinical researchers in women's health."

\section{Other Program Features}

At the start of the 2 year program, fellows and senior mentors will develop a training plan tailored to the background and interest of each fellow and the resources available at UC Davis. The Mentored Clinical Research Training Program trains clinical researchers through a multi-disciplinary didactic curriculum and mentored research experience. This approach allows the fellows to develop content and methodologic skills in clinical research. Participation in the Women's Assessment Center will allow clinical skills to be developed under the guidance and mentorship of a multi-disciplinary team of women's health providers including general internists, gynecologists, family medicine, psychiatry, endocrinology and cardiovascular medicine.

\section{Reason for Initiating Program}

"This fellowship program builds on the clinical and education success of UCD, the institution's commitment to women's health, and the availability of an extensive array of ongoing clinical programs and research projects relative to women's health; to develop a cadre of well-trained clinicians and clinical researchers in women's health." 


\section{Institution(s)}

University Hospitals of Cleveland-Case

Western Reserve University Department of Family Medicine (UH)

Program Type: Fellowship in Women's Health

Date Established: 1999

Number of Positions: 1 per year

Duration of Program: 12 months

Sponsored by:

Department of Family Medicine,

University Hospitals Case Medical

Center

Co-Sponsoring Institution(s)/Department(s) Louis Stokes Wade Park Veteran's

Administration Hospital, Department of Medicine (VA)

Contact(s)

Al Cadesky MD, Fellowship Director

c/o Sandra Berk

1100 Euclid Avenue

Cleveland, OH 44106-5036

Telephone: (216) 844-3791

FAX: (216) 844-3799

E-mail: alan.cadesky@uhhospitals.or

\section{Eligibility Requirement(s)}

Completion of residency in Family Medicine or $\mathrm{ABFM}$ certification is required

\section{Required Activities}

1. Precepting Medicine residents, performing Gyn procedures with a supervising OB/Gyn attending, and triaging abnormal Paps and mammograms for management at the weekly VA Gyn/Urgent Followup/Preventive Health clinic 2. Coordinate weekly Women's Health lecture series for residents and medical students at the VA, including giving short talks on Women's Health topics and scheduling visiting lecturers

3. Scholarly activity at the VA on an ongoing project or other of your choosing

4. Patient care in UH Family Medicine Center, including option for encouragement of small continuity OB practice under preceptorship of Family Medicine attendings

5. Medical student teaching at $\mathrm{UH}$ both during patient care sessions and for required core clerkship in Medicine/Family Medicine in small group lectures and workshops

6. Colposcopy course director and faculty for UH Family Medicine PGY2 course

7. Precepting Family Medicine residents at Adolescent Clinic, Free Clinic of Greater Cleveland, and Care Alliance Health Center (homeless clinic), in rotation with other fellows

\section{Elective Activities}

Gender-focused longitudinal or block experiences at the VA and/or UH in female urology/ urogynecology, Gyn, rheumatology, hematology-oncology, breast surgery, sports medicine, prevention, female psychiatry, sexual medicine, addiction/PTSD and others, tailored to your needs and interests.

\section{Special Degree(s)/Certificate(s) Offered}

Letter of completion

\section{Goals of the Program}

"The fellowship is intended to provide expanded training in various aspects of Women's Health while maintaining proficiency in the wider discipline of Family Medicine."

\section{Other Program Features}

The curriculum consists of a series of longitudinal clincal experiences as clinician and preceptor, electives in various subspecialties with a gender-based focus, education of students and resident peers and participation in scholarly activity. The residents divide their time between the two locations above.

\section{Reason for Initiating Program}

"To improve the health of women by training physicians in the comprehensive and complex needs of the female patient." 


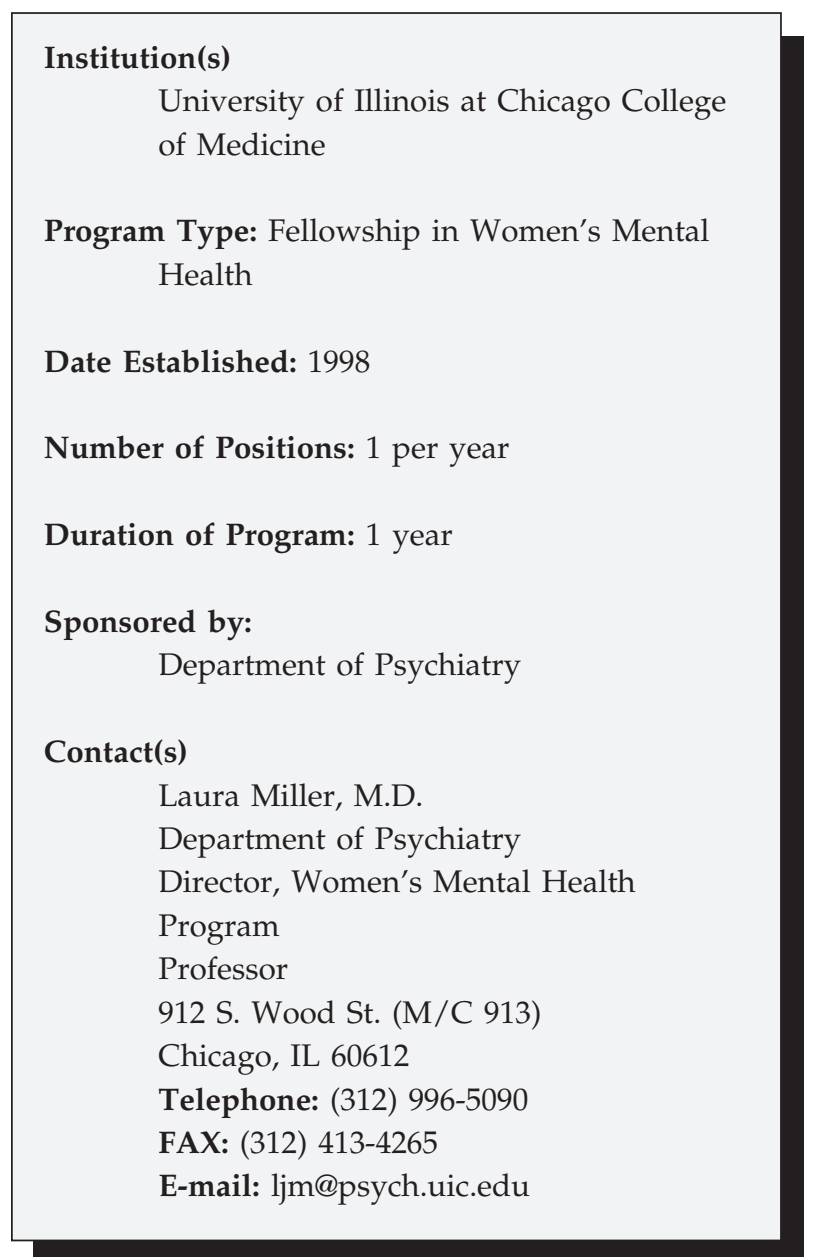

\section{Eligibility Requirement(s)}

Completion of at least 3 years postgraduate training in psychiatry.

\section{Required Activities}

Rotations through the Women's Clinic and Women's Consultation Service; participation in the Women's Mental Health Seminar, the Women's Mental Health Tutorial and the Women's Mental Health Forum; supervision of fourth-year medical students during Women's Mental Health electives

\section{Elective Activities}

Participation in the Illinois Perinatal Mental Health Project; rotations through the Women's Inpatient Treatment Service and/or the Eating Disorders Clinic; teaching in the Women's Mental Health Seminar.

\section{Special Degree(s)/Certificate(s) Offered}

None are offered.

\section{Goals of the Program}

"Fellows will acquire knowledge and skills related to the expression and treatment of psychiatric disorders in women, including their relationship to reproductive cycle events."

\section{Other Program Features}

Research experience related to women's mental health and a didactic curriculum in women's mental health are offered. Fellows will have opportunities to publish and review articles and/or book chapters. This program has received the American College of Psychiatrists' Award for Creativity in Psychiatric Education and the American Psychiatric Association's Gold Award for Innovative Services.

\section{Reason for Initiating Program}

"This fellowship was designed to train clinicians to meet the growing need for expertise in women's mental health by applying research findings to clinical practice, and teaching state-of-the-art interventions." 
University of Medicine and Dentistry of New Jersey/Robert Wood Johnson

Medical School

Program Type: Fellowship in Women's Health

Date Established: July 1992

Number of Positions: 1 per year

Duration of Program: 1 year

Sponsored by:

Department of Family Medicine

Co-Sponsoring Institution(s)/Department(s)

Department of Obstetrics, Gynecology, and Reproductive Science

Contact(s)

Jeffrey Levine, M.D., M.P.H.

Department of Family Medicine

UMDNJ-Robert Wood Johnson Medical

School

One Robert Wood Johnson Place, CN19

New Brunswick, NJ 08903-0019

Telephone: (732) 235-7670

(Administrative Assistant: Robin

Covington)

FAX: (732) 235-6309

E-mail: jeffzoo@aol.com

\section{Institution(s)}

\section{Eligibility Requirement(s)}

A New Jersey medical license and a completed residency in Family Medicine are required.

\section{Required Activities}

Original research and community service project design, implementation, and publication; Resident and medical student precepting on Gynecology rotations; Local and national CME/research presentations; Clinical rotations in selected areas of women's health and; Teaching and Research Skills Coursework.

\section{Elective Activities}

Fellows are encouraged to take a leadership role in addressing women's health issues most relevant to them, utilizing our educational, clinical, community, and legislative resources. Fellows are invited to participate in women's health related clinical trials, educational programs, and professional organizations.

\section{Special Degree(s)/Certificate(s) Offered}

None were specified.

\section{Goals of the Program}

“To develop leaders in women's health research, education, clinical care, and advocacy."

\section{Other Program Features}

The program offers flexibility. Clinical rotations and course work are adaptable to fellows' needs. Many resources are available throughout the state, including Rutgers University, CDC-STD training site, Planned Parenthood, and the three medical schools of the University of Medicine and Dentistry.

\section{Reason for Initiating Program}

"To develop and coordinate the essential resources and opportunities for Family Physicians to assume a leadership role in women's health care." 


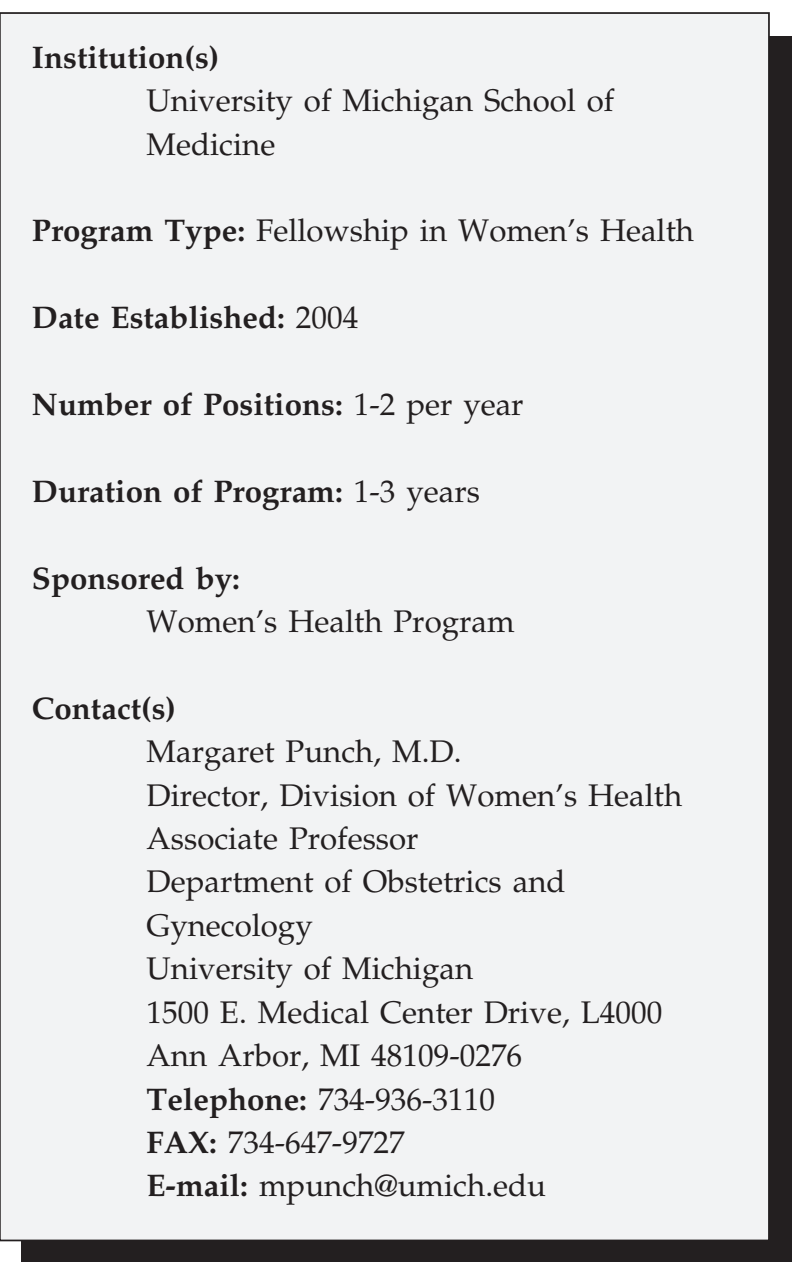

\section{Eligibility Requirement(s)}

Completion of residency in Family Medicine, Internal Medicine, Obstetrics/Gynecology, Pediatrics, or Psychiatry is required, further subspecialty training favorably considered.

\section{Required Activities}

Selected rotations in the Women's Health Clinic, Obstetrics and Gynecology Primary Care Clinic, Endocrinology and Metabolism Eating Disorders Clinic, Women's Heart Clinic, Women's GI Clinic, Women's Mental Health Clinic, Sexual Dysfunction Clinic, Women's Geriatric Clinic. Attend University of Michigan BIRCWH Seminar Series.

\section{Elective Activities}

Family Planning, Adolescent Gynecology, International Rotation, Institute for Research on Women and Gender

\section{Special Degree(s)/Certificate(s) Offered}

MPH, MS (Clinical Design and Statistical Analysis, Health Services Research or Health Care Research) or MHSA are available.

\section{Goals of the Program}

"Unsurpassed preparation for clinically focused Women's Health specialty or academic Women's Health careers."

\section{Other Program Features}

The fellowship offers a one year clinical training fellowship with selected rotations at the various entities within the Women's Health Program at the University of Michigan. All fellows will have a clinical mentorship team consisting of three faculty who will help design the program. For those fellows desiring further academic training or a Masters degree, an additional second or third year is available to allow for completion of course work, further clinical work, and/or 6 to 18 months dedicated to women's health research which would include original research, manuscript preparation, and grant preparation in conjunction with the other training and career development programs at the University of Michigan such as the BIRCWH training program and the Reproductive Sciences Training Program.

\section{Reason for Initiating Program}

"To train clinical and academic leaders in a rich collaborative environment utilizing the resources of the University of Michigan Women's Health Program." 


\section{Institution(s)}

University of Wisconsin School of

Medicine and Public Health/William S.

Middleton Veterans Hospital

Program Type: Fellowship in Women's Health

Date Established: May 1995

Number of Positions: 1-2 per year

Duration of Program: 2-5 years

Sponsored by:

University of Wisconsin Center for

Women's Health Research

Women's Veterans Health Program

Co-Sponsoring Institution(s)/Department(s)

Departments of Medicine, Psychiatry, and OB/GYN

Contact(s)

Molly Carnes, M.D., M.S.

Professor of Medicine, Psychiatry, and Industrial \& Systems Engineering University of Wisconsin Center for Women's Health Research 700 Regent Street, Suite 301 Madison, WI 53715

Telephone: (608) 263-9770

FAX: (608) 265-6423

E-mail: mlcarnes@wisc.edu

\section{Eligibility Requirement(s)}

Applicants must be board certified or board eligible in Internal Medicine, Psychiatry, Ob/Gyn, or Family Medicine.

\section{Required Activities}

Weekly multidisciplinary clinic, monthly administrative and research conference, monthly Women's Health Forum, annual presentation to Advisory Committee, annual Women's Health and Leadership Conference, and annual Center Advisory Board meeting.

\section{Elective Activities}

A full spectrum of supplemental clinical, didactic, basic or applied research activities are available.

\section{Special Degree(s)/Certificate(s) Offered}

Most fellows enroll in a graduate degree program: usually the MS or PhD program in Population Health or graduate certificate program in Clinical Investigation.

\section{Goals of the Program}

To train future leaders in academic health sciences.

\section{Other Program Features}

This program integrates with several NIH training and career development programs in women's health.

\section{Reason for Initiating Program}

We saw women's health research, including the study of sex- and gender-differences, as legitimate venues to attract and retain talented women into academic career pathways with leadership trajectories. 
Institution(s)

VA Greater Los Angeles Healthcare System (CA)

Program Type: Fellowship in Women's Health

Date Established: 1992

Number of Positions: 2 per year

Duration of Program: 2 years

Sponsored by:

VA Special Fellowship Program

Co-Sponsoring Institution(s)/Department(s)

UCLA Medical Center/RAND

Contact(s)

Program Directors:

Lisa Altman, M.D.

Clinical Director, Women's Health

Donna Washington, MD

VA GLA Women's Health

Contact for Applicants:

Joyce Holcomb

Program Analyst, Women's Health

16111 Plummer Street

Sepulveda, CA 91343

Telephone: 818-895-9555

Fax: 818-895-9453

E-Mail: joyce.holcomb@va.gov

Vera Snyder-Schwartz

Health Science Specialist

16111 Plummer Street

Sepulveda, CA 91343

Telephone: 818-891-7711 x5488

Fax: 818-895-9449

E-Mail: vera.snyder@va.gov

\section{Eligibility Requirement(s)}

Completion of an accredited residency training program, US citizenship, board eligible for internal medicine, OB/GYN, family medicine, psychiatry and surgery.

\section{Required Activities}

$75 \%$ time research, including master's level classes in epidemiology and statistics, and teaching interns/residents; and 25\% clinical time.

\section{Elective Activities}

No information provided.

\section{Special Degree(s)/Certificate(s) Offered}

Master's in Public Health

\section{Goals of the Program}

"To improve women veterans' access to coordinated, comprehensive, compassionate medical, surgical, and psychosocial care with a major focus on prevention and education; also to train physicians to excel in women's healthcare."

\section{Other Program Features}

This fellowship, funded by the Department of Veterans Affairs, is open to primary care physicians, obstetricians and gynecologists who are interested in research in women's health. Fellows in this program also develop competencies in clinical care for women, including performance and minor gynecologic procedures, through the VA Women's Health Center program. Fellows complete a core curriculum including formal course work, usually leading to a degree, at the UCLA School of Public Health; informal course work in fellowship seminars; and an independent research project.

\section{Reason for Initiating Program}

"To provide comprehensive, coordinated healthcare and education, based on women's lifecycles, to female veterans and allow Fellows a multidisciplinary clinical practice and research opportunities." 


\section{Integrated Residency Models}

Three training programs in traditional primary care tracks are highlighted as integrated models for a multidisciplinary approach to training of healthcare professionals in women's health. 


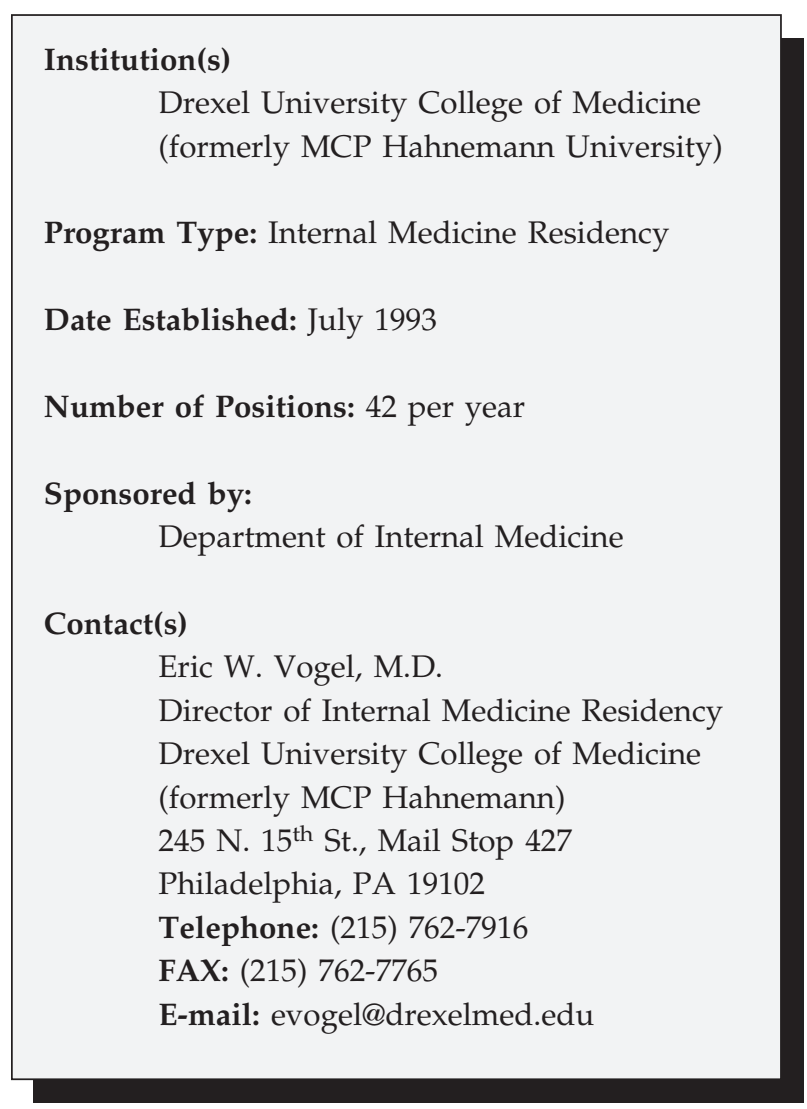

Goals of the Program

"To provide optimal medical care to all patients."

\section{Eligibility Requirement(s)}

A medical degree is required.

\section{Required Activities}

The following clinics are offered: 1) evening session performing pelvic exams on standardized patients; 2) two-week rotation at a sexually transmitted diseases clinic; 3) ten half-day sessions in Gynecology and Family Planning clinic; and 5) attendance at didactic lectures and journal clubs, which include women's issues.

\section{Elective Activities}

1) A four-week rotation at the Center's for Women's Health, a busy multi-disciplinary outpatient practice focusing on women's health issues 2) Primary Care/Continuity clinic one-half day per week at the Centers for Women's Health, seeing an ongoing panel of female patients under the supervision of the Women's Health General Internal Medicine attendings.

\section{Special Degree(s)/Certificate(s) Offered}

Special degrees and certificates are not offered.

\section{Other Program Features}

Women's health issues are addressed daily in all aspects of the residency program, including daily rounds, morning report, journal club, and didactic conferences.

\section{Reason for Initiating Program}

"To do the right thing. We want to provide optimal care for all patients, so we established specific Women's Health clinical and educational activities, to address deficiencies in caring for this major sector of the population." 


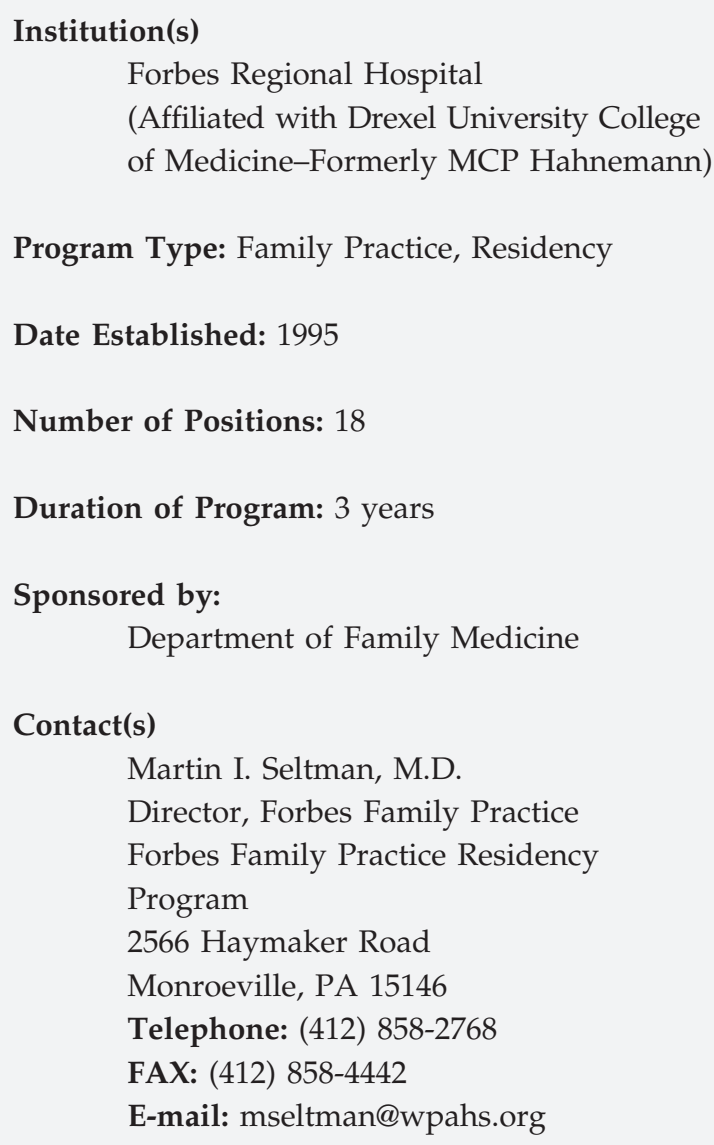

Program Type: Family Practice, Residency

Date Established: 1995

Number of Positions: 18

Duration of Program: 3 years

Sponsored by:

Department of Family Medicine

Contact(s)

Martin I. Seltman, M.D.

Director, Forbes Family Practice

Forbes Family Practice Residency

Program

2566 Haymaker Road

Monroeville, PA 15146

Telephone: (412) 858-2768

FAX: (412) 858-4442

E-mail: mseltman@wpahs.org

\section{Eligibility Requirement(s)}

A medical degree or doctor of osteopathic medicine degree is required.

\section{Required Activities}

Residents must complete the Family Practice Medicine program. Women's health curricula are integrated throughout the residency program.

\section{Elective Activities}

Residents may elect two 1-month electives, and a one 6-month one-half day per week longitudinal elective or elect two 1-month electives. These electives focus on a particular area of women's health.

\section{Special Degree(s)/Certificate(s) Offered}

Residents are board eligible in Family Practice.

\section{Goals of the Program}

"The goals of the program are to achieve competence in Family Practice, including health care for women from a feminist perspective, based on the voiced experiences of each woman and evidencebased, sex and gender-specific science."

\section{Other Program Features}

This program includes an integrated curriculum in women's health drawing from the fields of women's studies and women's history, and focuses on specific expertise in reproductive health within family practice.

\section{Reason for Initiating Program}

"The Forbes Family Practice Residency Program has had a long and serious interest in promoting women's health within its residency program." 


\section{Institution(s)}

Long Island Jewish Medical Center

Program Type: Obstetrics and Gynecology Residency

Date Established: June 1993

Number of Positions: 5 per year

Duration of Program: 4 years

Sponsored by:

Department of Obstetrics and

Gynecology

\section{Contact(s)}

Vicki Seltzer, M.D.

Chairman, Department of Obstetrics and Gynecology

Long Island Jewish Medical Center 270-05 76th Avenue

New Hyde Park, NY 11040

Telephone: (718) 470-7660

FAX: (718) 962-6739

E-mail: vseltzer@lij.edu

\section{Eligibility Requirement(s)}

A medical degree is required.

\section{Required Activities}

In addition to Obstetrics and Gynecology training, residents receive comprehensive education in primary and preventive women's health care in an ambulatory setting.

\section{Special Degree(s)/Certificate(s) Offered}

Residents are board eligible in Obstetrics and Gynecology.

\section{Elective Activities}

Information was not provided.

\section{Goals of the Program}

"To enable the graduate to provide the complete range of preventive and ambulatory primary health care services to women, as well as the entire range of OB/GYN services."

\section{Other Program Features}

This residency has been restructured to provide broad-based education in women's primary health care.

\section{Reason for Initiating Program}

"To enhance education in women's primary health care so that women will be able to receive coordinated care from a single provider." 